\title{
Effects of irrigation fluid temperature during flexible ureteroscopic holmium laser lithotripsy on postoperative fever and shivering: a randomized controlled trial
}

Yue He ${ }^{1,2^{*}}$, You-Gang Feng ${ }^{1}$, Jun He ${ }^{1}$, Bo Liang ${ }^{1}$, Ming-Dong Jiang ${ }^{1}$, Jun Liu' ${ }^{1}$, Yong-Ming Kang ${ }^{1}$, Li-Ping Ma ${ }^{3}$, Qin Zhang ${ }^{3}$, Qi-Jia Peng ${ }^{3}$, Tao Yang ${ }^{1}$, Yao Liu ${ }^{3}$, Li Luo ${ }^{4}$ and Min Zhang ${ }^{4}$

\begin{abstract}
Background: Flexible ureteroscopic holmium laser lithotripsy is used to treat urinary tract calculi, but postoperative complications include shivering, fever and infection. To investigate the effects of irrigation fluid temperature on postoperative complications.

Methods: This randomized controlled trial included 120 consecutive patients undergoing flexible ureteroscopic holmium laser lithotripsy at the Urology Department, Suining Central Hospital, Sichuan, China between January 2017 and July 2019. Patients were randomized 1:1:1 into three groups $\left(17^{\circ} \mathrm{C}, 27^{\circ} \mathrm{C}\right.$ or $\left.37^{\circ} \mathrm{C}\right)$. Primary outcome was fever incidence (body temperature $>37.5^{\circ} \mathrm{C}$ ) within $48 \mathrm{~h}$ after surgery. Secondary outcomes included shivering incidence during recovery from anesthesia, white blood cell count (WBC), serum procalcitonin (PCT) and incidence of suspected infection (temperature $>38.5^{\circ} \mathrm{C}$ and PCT $>0.5 \mu \mathrm{g} / \mathrm{L}$ ).

Results: There were 108 patients, $\left(17^{\circ} \mathrm{C}\right.$ group, $n=36 ; 27^{\circ} \mathrm{C}$ group, $n=35 ; 37^{\circ} \mathrm{C}$ group, $\left.n=37\right)$, received flexible ureteroscopic holmium laser lithotripsy and analyzed. Age, gender distribution, body mass index, ASA grade, stone burden, preoperative creatinine, preoperative core temperature and irrigation fluid volume did not differ significantly between groups. $17{ }^{\circ} \mathrm{C}, 27^{\circ} \mathrm{C}$ and $37^{\circ} \mathrm{C}$ groups exhibited significant differences in the incidences of postoperative fever (38.9\% vs. $17.1 \%$ vs. $13.5 \%$ ) and shivering ( $22.2 \%$ vs. $5.7 \%$ vs. $2.7 \%)$ ( $p<0.05$ for all pairwise comparisons). There was no significant difference of WBC, PCT and incidence of suspected infection in $37^{\circ} \mathrm{C}$ or $27^{\circ} \mathrm{C}$ group compared with $17{ }^{\circ} \mathrm{C}$ group. One case each of flash pulmonary edema and bleeding occurred in $37^{\circ} \mathrm{C}$ group.

Conclusion: Warming the irrigation fluid can reduce the incidence of postoperative fever and shivering, but further studies are needed to determine the optimal temperature.

Trial registration The trial was registered at the Chinese Clinical Trials Registry and allocated as ChiCTR2000031683. The trial was registered on 07/04/2020 and this was a retrospective registration.
\end{abstract}

Keywords: Irrigation fluid, Temperature, Flexible ureteroscopic holmium laser lithotripsy, Calculi, Holmium: YAG laser

*Correspondence: 330275636@qq.com

1 Department of Urology, Suining Central Hospital, No. 127 Desheng W. Rd., Chuanshan District, Suining City 629000, Sichuan Province, People's Republic of China

Full list of author information is available at the end of the article

\section{Background}

Calculi can develop in the urinary tract when the urine becomes supersaturated with a mineral, leading to the formation of crystals comprised of calcium oxalate, calcium phosphate, uric acid or other substances [1]. The 
prevalence of urinary calculi is higher in developed countries than in developing countries and has been estimated to be around $9 \%$ in the USA and $4 \%$ in China [2]. Factors associated with an increased risk of urinary calculi in adulthood include male gender, obesity and diabetes mellitus [1]. Urinary stones often present acutely with pain, infection or hematuria, necessitating treatment. A variety of medical [3] and surgical $[4,5]$ therapies are available for the treatment of urinary calculi, including stone fragmentation by lithotripsy [6].

The development of endoscopic technology and lithotripsy techniques for the treatment of urinary calculi has led to traditional open surgery being replaced by endoscopic procedures [7]. Ureteroscopes introduced via the urethra can reach upper urinary tract calculi in the ureter, renal pelvis and calyces, permitting holmium laser lithotripsy to be carried out as a treatment [8]. The latest recommendations of the European Association of Urology, which were published in 2019, recommend flexible ureteroscopic lithotripsy as the first-line surgical treatment option for proximal ureteral/renal calculi with a diameter $<20 \mathrm{~mm}$ [9]. However, postoperative complications occur in $2.5-6.7 \%$ of patients after ureteroscopic stone treatment [10-13], and fever is the most common postoperative complication of ureteroscopic holmium laser lithotripsy [10, 11, 14-18]. Therefore, there is great interest in identifying methods to reduce the incidence of fever after ureteroscopic holmium laser lithotripsy.

The use of irrigation fluid is essential during transurethral endoscopic surgery. Flexible ureteroscopic lithotripsy is often performed with continuous saline irrigation through the working channel to improve the visibility when an instrument is inserted, particularly during stone dusting or when a small venous bleed occurs. Warming the irrigation fluid has been shown to reduce the incidence of hypothermia and shivering during transurethral resection of the prostate (TURP) [19]. Furthermore, the use of isothermic irrigation fluid can help to maintain normal body temperature and avoid hypothermia during percutaneous nephrolithotripsy (PCNL) [20]. However, the effects of irrigation fluid temperature during flexible ureteroscopic holmium laser lithotripsy on body temperature and the postoperative incidences of shivering, fever, infection and other complications remain unknown.

We hypothesized that increasing the temperature of the irrigation fluid during flexible ureteroscopic holmium laser lithotripsy would reduce the incidence of shivering during recovery from anesthesia and fever during the 2-day period after the procedure. Therefore, the aim of this randomized controlled trial was to investigate the effects of irrigation fluid temperature during flexible ureteroscopic holmium laser lithotripsy on the incidence of short-term postoperative complications including fever and shivering.

\section{Methods \\ Study design}

This was a randomized controlled trial conducted at the Department of Urology, Suining Central Hospital, Sichuan, China between January 2017 and July 2019. The Ethics Committee of Suining Central Hospital, Sichuan Province, P.R. China approved the study. All patients read and understood written information describing the study aims and protocol, and all patients signed consent forms agreeing to participate in this clinical research.

\section{Patients}

Participants were enrolled using the following inclusion criteria: (1) age 18-70 years; (2) American Society of Anesthesiologists (ASA) grade I or II [21]; (3) diagnosis of unilateral proximal ureteral calculi and/or renal calculi made by computed tomography (CT); (4) diameters of all calculi were $<20 \mathrm{~mm}$; and (5) total stone burden was $<360 \mathrm{~mm} 2$. The exclusion criteria were as follows: (1) thyroid disease or dysautonomia; (2) bilateral upper urinary tract stones scheduled to be treated simultaneously during surgery; (3) preoperative fever; (4) urinary tract infection when included in the trial; (5) hydronephrosis $>3 \mathrm{~cm}$ on ultrasound; (6) ureteral stenosis.

\section{Randomization and blinding}

Patients were randomized $1: 1: 1$ to $37{ }^{\circ} \mathrm{C}$ group, $27{ }^{\circ} \mathrm{C}$ group or $17{ }^{\circ} \mathrm{C}$ group. The random sequence and grouping sequence were generated using the random function in Excel (Microsoft Corp., Redmond, WA, USA), and the generated random sequence was put into sequentially coded, sealed and opaque envelopes. The envelopes were kept by an investigator (TY) who did not participate in the recruitment of patients, intervention or outcome evaluation. The sealed envelope was brought into the operating room with the patient and opened by the anesthesiologist and nurse who were in charge of setting the temperature of the irrigation fluid during surgery.

\section{Intervention}

One week before the procedure, a ureteral stent was placed routinely to dilate the ureter. The irrigation fluid used during surgery was sterile physiological saline. The surgical nurse (MLP, ZQ, PQJ), who was responsible for setting the temperature of the irrigation fluid during the operation, placed the irrigation fluid into a medical incubator with a pre-set temperature $\left(37^{\circ} \mathrm{C}, 27^{\circ} \mathrm{C}\right.$ or $\left.17^{\circ} \mathrm{C}\right)$ $6 \mathrm{~h}$ before the procedure. The temperature of the irrigation fluid was $37^{\circ} \mathrm{C}$ for patients in $37^{\circ} \mathrm{C}$ group, $27^{\circ} \mathrm{C}$ for patients in $27{ }^{\circ} \mathrm{C}$ group, and $17{ }^{\circ} \mathrm{C}$ for patients in $17{ }^{\circ} \mathrm{C}$ 
group. Intravenous fluids were given at room temperature to patients in all three groups.

The procedure was carried out under general anesthesia with the patient in the lithotomy position and covered with a single layer of sterile surgical drape. The operating room temperature was adjusted to $24{ }^{\circ} \mathrm{C}$. The intraoperative core (tympanic) temperature was recorded by the anesthesiologist (ZM, LL) every 10 min until the end of the operation. No heating device was used until the core temperature dropped below $34{ }^{\circ} \mathrm{C}$. All procedures were performed by the same surgical team, which was led by a chief surgeon (HJ, HY, FYG) with previous experience of more than 50 ureteroscopic holmium laser lithotripsy procedures.

The Olympus URF-V electronic flexible ureteroscope were used in the operation. For irrigation, a 3-L bag of sterile $0.9 \% \mathrm{NaCl}$ solution was suspended $70 \mathrm{~cm}$ above the kidney. One end of the infusion tube was connected to the fluid bag, and the other end was connected to the water inlet switch of the flexible ureteroscope. The chief surgeon was able to use the water inlet switch to control the fluid inlet flow. In each case, ureteral access sheath (internal and external size: Fr12 and Fr14) was used. The laser fiber was $200 \mu \mathrm{m}$, and the basket was COOK (NGE017115-UDH-MB). Primary technique was dusting to break up the stones. The laser parameters: pulse energy $(1 \mathrm{~J})$, frequency $(20 \mathrm{~Hz})$. If the diameter is greater than $3 \mathrm{~mm}$, basket was used. A ureteral stent was placed routinely after surgery, about for one month after treatment. Following completion of the operation, the patient was transferred from the operating room to the post-anesthesia care unit (PACU) and returned to the general ward once fully awake. Routine blood tests, measurement of serum procalcitonin (PCT) and renal function tests were performed $24 \mathrm{~h}$ after surgery, and body temperature was recorded. The urinary catheter was removed $24 \mathrm{~h}$ after the operation, and the patient was discharged $48 \mathrm{~h}$ after surgery in the absence of serious complications.

\section{Clinical data and outcomes}

Each patient's age, gender, body mass index (BMI), preoperative serum creatinine level, ASA grade, stone location and stone burden were recorded before the intervention. Postoperative parameters including core body temperature at the end of surgery, occurrence of postoperative shivering, maximum body temperature during the $48 \mathrm{~h}$ after the operation, white blood cell (WBC) count, serum PCT level, serum creatinine level and duration of hospitalization were also collected for analysis.

Stone burden was defined as the two-dimensional area determined by multiplying the longest diameter by the perpendicular diameter of the stone [22]. In cases of multiple stones, the total (cumulative) stone burden was calculated as the sum of the burden of each stone. Postoperative fever was defined as any temperature reading above $37.5{ }^{\circ} \mathrm{C}$. The combination of body temperature $>38.5^{\circ} \mathrm{C}$ and $\mathrm{PCT}>0.5 \mu \mathrm{g} / \mathrm{L}$ was considered as suspected infection, necessitating further investigation and the administration of antibiotics and/or delay of discharge, as necessary.

The primary outcome of this study was the incidence of fever (body temperature $>37.5{ }^{\circ} \mathrm{C}$ within $48 \mathrm{~h}$ after the operation). The secondary outcomes were the incidence of shivering during recovery from anesthesia, WBC count, serum PCT level, incidence of suspected infection and length of hospital stay. Complications were classified according to the modified Clavien-Dindo grading system [23].

\section{Sample size}

Calculation of sample size was done on the basis of the formula $\mathrm{n}=\frac{1641.6 \lambda}{\left(\sin ^{-1} \sqrt{\text { Pmax }}-\sin ^{-1} \sqrt{\text { Pmin })^{2}}\right.}$, assuming a statistical power ( $\beta$ ) of $90 \%$ and an $\alpha$ error of $5 \%$. According to the literature, the incidence of fever following ureteroscopy is less than $5 \%$. Using estimated fever rates of $P \min =5 \%$ and $P \max =35 \%$, the calculated minimum sample size for each group was $n=38$. Assuming a rate of exclusion or loss to follow-up of $5 \%$, the study was designed to include 40 patients in each group.

\section{Statistical analysis}

The data were analyzed using SPSS 19.0 (IBM Corp., Armonk, NY, USA). Normally-distributed continuous data are described as mean \pm standard deviation and were compared between groups using one-way analysis of variance (ANOVA) and the Bonferroni post-hoc test. Non-normally distributed data are described as median (range) and were compared between groups using the Kruskal Wallis $\mathrm{H}$ test. Dunnett's test was used to perform multivariate comparisons between $37^{\circ} \mathrm{C}$ group and $27^{\circ} \mathrm{C}$ group, $17{ }^{\circ} \mathrm{C}$ group, respectively. Qualitative data were analyzed using Pearson's chi squared test or Fisher's exact test with Bonferroni correction for multiple comparisons. A $p$-value $<0.05$ was accepted as statistically significant.

\section{Results}

\section{Enrolment of the study participants}

Among 120 patients initially randomized to the three study groups, a total of 12 patients were subsequently excluded from the analysis due to refusal to participate in the trial $(n=3)$, refusal of flexible ureteroscopic holmium laser lithotripsy in favor of extracorporeal shock wave 
lithotripsy or PCNL $(n=3)$, duration of surgery $>90 \mathrm{~min}$ $(\mathrm{n}=2)$, ureteral stenosis $(\mathrm{n}=2)$ or nonideal positioning or displacement of the ureteral stent $(\mathrm{n}=2)$. Therefore, the final analysis included 37 patients in $37{ }^{\circ} \mathrm{C}$ group, 35 patients in $27{ }^{\circ} \mathrm{C}$ group and 36 patients in $17{ }^{\circ} \mathrm{C}$ group (Fig. 1).

\section{Preoperative clinical characteristics}

There were no significant differences between the three groups in age, sex distribution, BMI, stone location, stone burden, ASA grade or preoperative serum creatinine level (Table 1).

\section{Intraoperative characteristics}

The volume of intraoperative irrigation fluid used and operation time did not differ significantly between groups (Table 2). Core body temperature declined during surgery in all three groups but tended to decrease most rapidly in $17{ }^{\circ} \mathrm{C}$ group and most slowly in $37^{\circ} \mathrm{C}$ group (Fig. 2). Although preoperative core body temperature did not differ significantly between groups, core body temperature at the end of surgery was significantly lower in $17{ }^{\circ} \mathrm{C}$ group than in $27^{\circ} \mathrm{C}$ group or $37^{\circ} \mathrm{C}$ group $(p<0.05$; Table 2).

\section{Primary and secondary outcomes}

The incidence of postoperative fever (core body temperature $>37.5^{\circ} \mathrm{C}$ during the $48 \mathrm{~h}$ after surgery) differed significantly between $37^{\circ} \mathrm{C}$ group $(5 / 37,13.5 \%), 27^{\circ} \mathrm{C}$ group $(6 / 35,17.1 \%)$ and $17^{\circ} \mathrm{C}$ group $(14 / 36,38.9 \%)(p<0.05$ for all pairwise comparisons; Table 2). Similarly, the incidence of postoperative shivering differed significantly between $37{ }^{\circ} \mathrm{C}$ group $(1 / 37,2.7 \%), 27{ }^{\circ} \mathrm{C}$ group $(2 / 35$, $5.7 \%)$ and $17{ }^{\circ} \mathrm{C}$ group $(8 / 36,22.2 \%)(p<0.05$ for all pairwise comparisons; Table 2).

Postoperatively there were no significant differences between groups in the incidence of suspected infection (core body temperature $>38.5{ }^{\circ} \mathrm{C}$ and $\mathrm{PCT}>0.5 \mu \mathrm{g} / \mathrm{L}$ ), WBC count, PCT level or creatinine level, duration of hospital stays (Table 2).

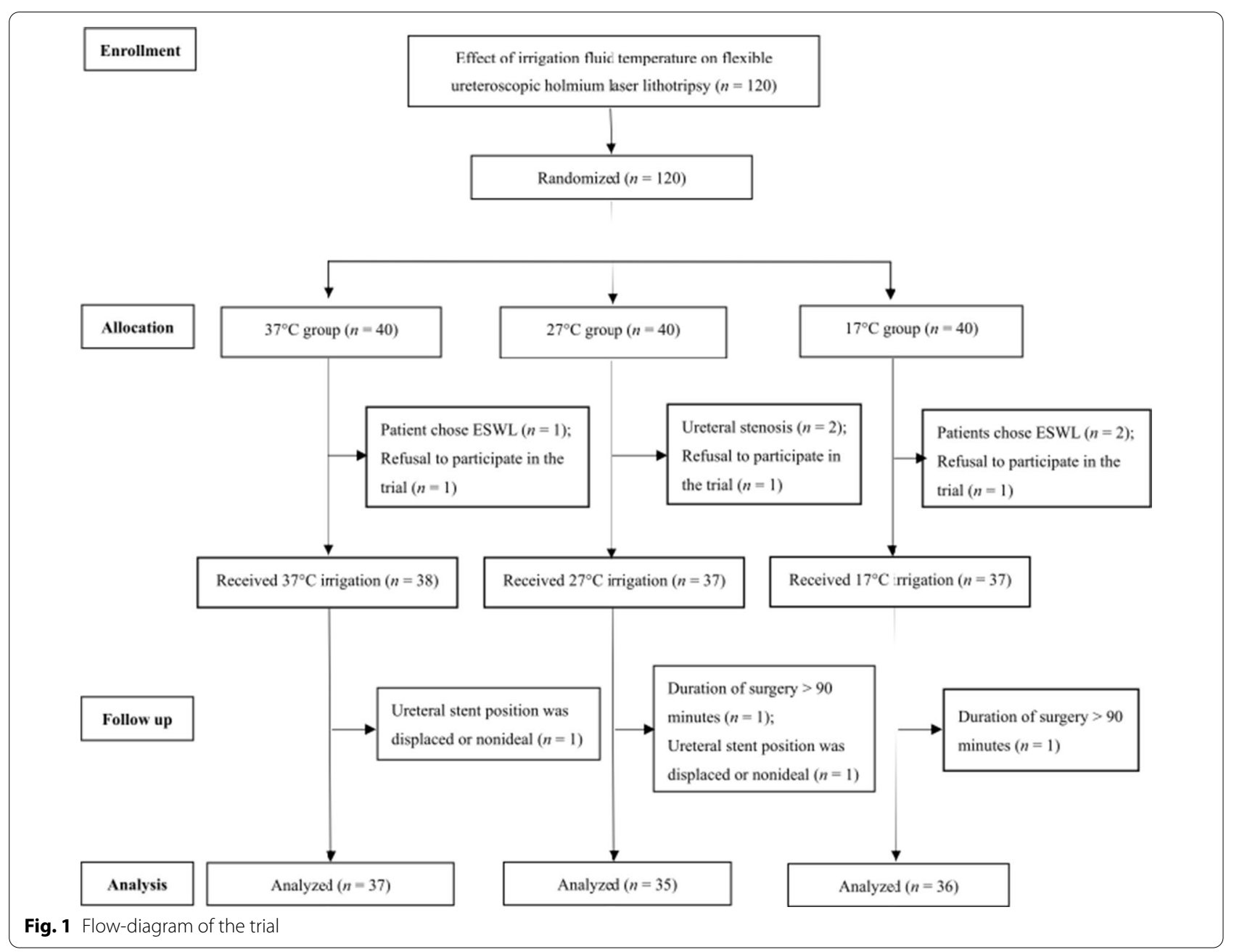


Table 1 Preoperative clinical characteristics of the study participants

\begin{tabular}{|c|c|c|c|c|}
\hline & $37^{\circ} \mathrm{C}(n=37)$ & $27^{\circ} \mathrm{C}(n=35)$ & $17^{\circ} \mathrm{C}(n=36)$ & $p$ \\
\hline Male, n (\%) & $20(54.1 \%)$ & $16(45.7 \%)$ & $19(52.8 \%)$ & 0.750 \\
\hline Female, n (\%) & $17(45.9 \%)$ & $19(54.3 \%)$ & $17(47.2 \%)$ & \\
\hline Age (years) & $42.8 \pm 12.3$ & $44.9 \pm 13.1$ & $44.3 \pm 11.7$ & 0.758 \\
\hline Body mass index $\left(\mathrm{kg} / \mathrm{m}^{2}\right)$ & $24.11 \pm 2.88$ & $24.17 \pm 2.69$ & $24.26 \pm 3.02$ & 0.973 \\
\hline Preoperative creatinine ( $\mu$ mol/L) & $93.0 \pm 19.0$ & $92.6 \pm 20.0$ & $94.1 \pm 18.6$ & 0.942 \\
\hline \multicolumn{5}{|l|}{ ASA grade, $n(\%)$} \\
\hline । & $23(62.2 \%)$ & $21(60.0 \%)$ & $20(55.6 \%)$ & 0.843 \\
\hline$\|$ & $14(37.8 \%)$ & $14(40.0 \%)$ & $16(44.4 \%)$ & \\
\hline \multicolumn{5}{|l|}{ Stone location, n (\%) } \\
\hline Kidney & $9(24.3 \%)$ & $7(20.0 \%)$ & $11(30.6 \%)$ & 0.830 \\
\hline Ureter & $9(24.3 \%)$ & $8(22.9 \%)$ & $6(16.7 \%)$ & \\
\hline Kidney and ureter & $19(51.4 \%)$ & $20(57.1 \%)$ & $19(52.7 \%)$ & \\
\hline Stone burden $\left(\mathrm{mm}^{2}\right)$ & $109(40-266)$ & $123(48-304)$ & $140(45-266)$ & 0.670 \\
\hline
\end{tabular}

Data are presented as $n$ (\%), mean \pm standard deviation or median (range). ASA, American Society of Anesthesiologists

Table 2 Perioperative and postoperative characteristics

\begin{tabular}{|c|c|c|c|c|}
\hline & $\begin{array}{l}37^{\circ} \mathrm{C} \\
(n=37)\end{array}$ & $\begin{array}{l}27^{\circ} \mathrm{C} \\
(n=35)\end{array}$ & $\begin{array}{l}17^{\circ} \mathrm{C} \\
(n=36)\end{array}$ & $p$ \\
\hline Irrigation fluid volume $(\mathrm{L})$ & $1.58 \pm 0.47$ & $1.69 \pm 0.51$ & $1.77 \pm 0.56$ & 0.274 \\
\hline Operative time (min) & $59.5 \pm 14.2$ & $60.7 \pm 15.3$ & $63.1 \pm 14.6$ & 0.573 \\
\hline Core temperature at start of surgery $\left({ }^{\circ} \mathrm{C}\right)$ & $36.59 \pm 0.27$ & $36.56 \pm 0.25$ & $36.59 \pm 0.29$ & 0.858 \\
\hline Core temperature at end of surgery $\left({ }^{\circ} \mathrm{C}\right)$ & $35.91 \pm 0.36^{*}$ & $35.56 \pm 0.32^{*}$ & $35.24 \pm 0.36$ & $<0.001$ \\
\hline Shivering during resuscitation from anesthesia & $1(2.7 \%)^{* \Delta}$ & $2(5.7 \%)^{*}$ & $8(22.2 \%)$ & 0.023 \\
\hline Postoperative creatinine $(\mu \mathrm{mol} / \mathrm{L})$ & $96.0 \pm 19.7$ & $94.0 \pm 20.6$ & $97.0 \pm 19.5$ & 0.815 \\
\hline Maximum $\mathrm{T}\left({ }^{\circ} \mathrm{C}\right)$ & $37.2(36.6-39.6)^{* \Delta}$ & $37.4(36.9-39.7)$ & $37.45(36.9-40.0)$ & 0.028 \\
\hline White blood cell count $\left(\times 10^{9} / \mathrm{L}\right)$ & $9.20 \pm 2.58$ & $9.43 \pm 2.16$ & $10.20 \pm 2.43$ & 0.175 \\
\hline Serum procalcitonin (ng/mL) & $0.15(0.03-0.60)$ & $0.15(0.05-0.95)$ & $0.15(0.05-0.97)$ & 0.625 \\
\hline Fever & $5(13.5 \%)^{* \Delta}$ & $6(17.1 \%)^{*}$ & $14(38.9 \%)$ & 0.022 \\
\hline Suspected infection ${ }^{a}$ & $3(8.1 \%)$ & $2(5.7 \%)$ & $5(13.9 \%)$ & 0.505 \\
\hline Median hospital stays (days) & $3(3-7)$ & $3(3-7)$ & $3(3-7)$ & 0.060 \\
\hline
\end{tabular}

Data are presented as $\mathrm{n}(\%)$, mean \pm standard deviation or median (range). T, temperature

${ }^{*} p<0.05$ versus $17^{\circ} \mathrm{C}$ group; $\Delta p<0.05$ versus $27^{\circ} \mathrm{C}$ group

${ }^{\text {a }}$ Suspected infection was defined as core body temperature $>38.5^{\circ} \mathrm{C}$ and serum procalcitonin level $>0.5 \mu \mathrm{g} / \mathrm{L}$

\section{Other complications}

There was one case of flash pulmonary edema (the patient recovered and was discharged after medical therapy) and one case of postoperative hemorrhage (which stopped 3 days after placement of a three-cavity catheter for bladder irrigation) in $37{ }^{\circ} \mathrm{C}$ group. There was one case of urinary retention (the catheter was successfully removed after 1 week) in $37^{\circ} \mathrm{C}$ group and one case of ureteral abrasion (the ureteral stent was removed two months later) in $17^{\circ} \mathrm{C}$ group. There were no adverse events above grade III (Clavien-Dindo grading system) in this study.

\section{Discussion}

Important findings of the present study were that the incidences of postoperative fever and shivering decreased significantly as the temperature of the irrigation fluid was increased from 17 to $37{ }^{\circ} \mathrm{C}$. Postoperative WBC count, serum PCT level and incidence of suspected infection were comparable between groups. Although there was one case of flash pulmonary edema and one case of bleeding in $37^{\circ} \mathrm{C}$ group, both complications resolved after therapy. Our novel findings suggest that isothermic irrigation during flexible ureteroscopic holmium laser lithotripsy can reduce the incidence of postoperative fever and shivering. However, further studies are 


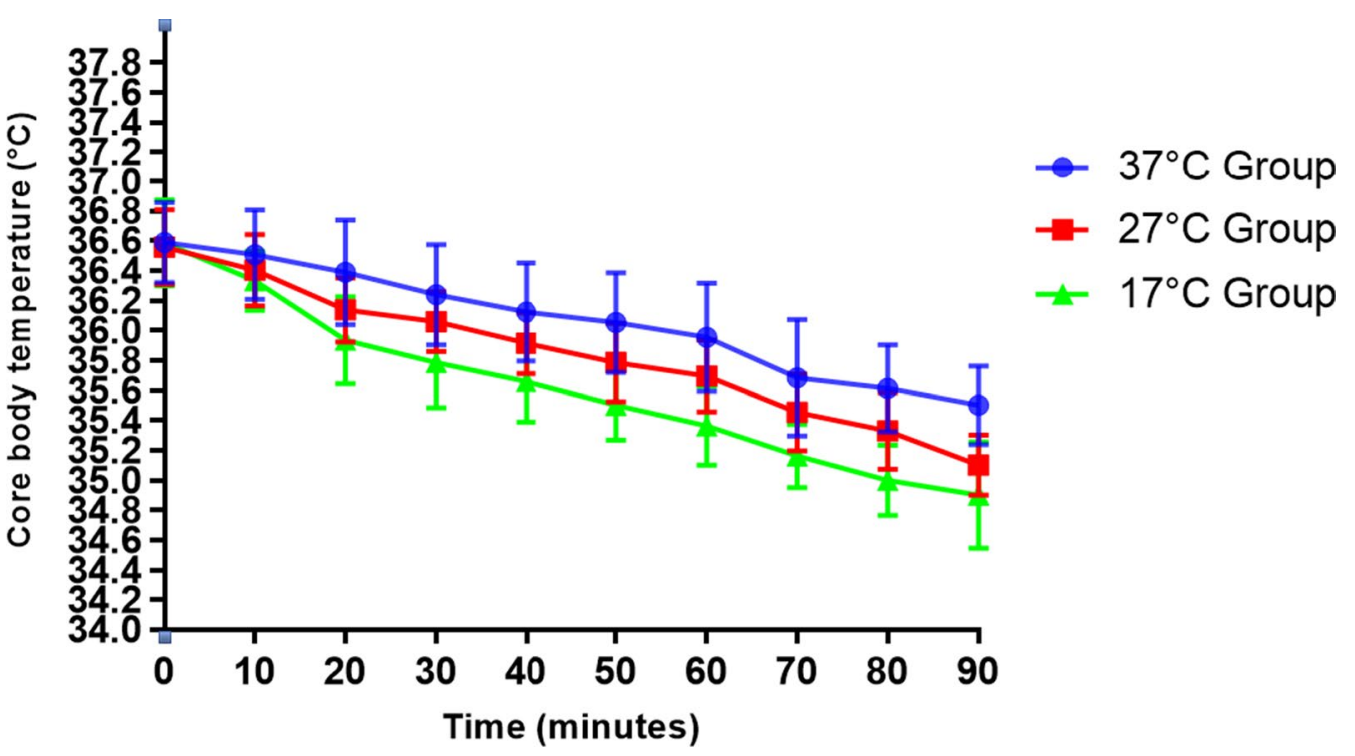

Fig. 2 Intraoperative core body temperature for patients in the three groups

required to establish the optimal temperature for the irrigation fluid.

There are many potential causes of fever after ureteroscopic holmium laser lithotripsy, including ureteral obstruction by stone fragments, urinary tract infection, intraoperative backflow and extravasation of urine due to prolonged high-pressure irrigation, intraoperative and postoperative bleeding, and postoperative backflow of urine in the bladder and ureter due to poor drainage via the catheter [24]. Furthermore, hypothermia and shivering can occur due to the large amounts of intravenous and irrigation fluids administered during surgery and anesthesia [25], particularly given that a substantial amount of irrigation fluid is absorbed by the patient $[26$, 27]. The present study investigated the effects of varying the temperature of the irrigation fluid on core body temperature during surgery and the incidence of postoperative fever while minimizing the influence of possible confounding factors. For example, all procedures were performed by the same experienced surgical team, irrigation fluid pressure was standardized and maintained below $40 \mathrm{mmHg}$ by suspending the liquid bag at the same height, and patients with preoperative urinary tract infection or postoperative ureteral stent displacement were excluded from the analysis.

In this study, core body temperature at the end of the procedure was significantly lower in $17{ }^{\circ} \mathrm{C}$ group than in the other two groups, indicating that the use of irrigation fluid at the lower temperature $\left(17^{\circ} \mathrm{C}\right)$ contributed to the fall in body temperature during surgery. By contrast, core body temperature at the end of the operation did not differ significantly between $37{ }^{\circ} \mathrm{C}$ group and $27^{\circ} \mathrm{C}$ group, indicating that additional heating of the irrigation fluid from 27 to $37^{\circ} \mathrm{C}$ was not beneficial for maintaining body temperature during surgery. This may have been due to the energy generated by the holmium laser during the operation, which increased the local temperature and heated the irrigation fluid [28].

The main finding of this study was that the incidence of postoperative fever (core body temperature $>37.5^{\circ} \mathrm{C}$ during the $48 \mathrm{~h}$ after surgery) was significantly lower in $27^{\circ} \mathrm{C}$ group than in $17^{\circ} \mathrm{C}$ group and significantly lower in $37^{\circ} \mathrm{C}$ group than in both the other groups. However, there were no significant differences between the three groups in the postoperative WBC count, serum PCT level or incidence of suspected infection (core body temperature $>38.5{ }^{\circ} \mathrm{C}$ and PCT $>0.5 \mu \mathrm{g} / \mathrm{L}$ ) [29]. The above results suggest that the differences in the incidences of fever between groups were not due to differences in the incidences of infection, further implying that the temperature of the irrigation fluid has little influence on the incidence of postoperative urinary tract infection. The use of hypothermic irrigation fluid can cause intraoperative hypothermia, and the risk of postoperative shivering is increased when core body temperature drops below $36^{\circ} \mathrm{C}$ [30]. A recent metaanalysis of 28 randomized controlled trials found that the fall in body temperature during surgical treatment of benign prostatic hypertrophy and the incidence of postoperative shivering were lower for warm irrigation fluid than for room-temperature irrigation fluid [19]. Therefore, our findings are in good agreement with the results of the above meta-analysis [19] and with other studies 
evaluating the effects of irrigation fluid temperature on body temperature $[31,32]$. Our observation that the incidence of postoperative fever increased as the irrigation fluid temperature was decreased (from 37 to $17^{\circ} \mathrm{C}$ ) might be explained by a compensatory reaction of the body to hypothermia at the end of surgery, with the shivering mechanism possibly contributing to this.

The incidence of postoperative fever in this study was relatively high in comparison to that reported by previous studies, ranging from 13.5 to $38.9 \%$. This may have been due to the wide definition of fever used in this study, since the patient was classified as having fever even if only one temperature reading was above $37.5{ }^{\circ} \mathrm{C}$ during the $48 \mathrm{~h}$ after surgery. Ten patients $(9.2 \%)$ had a postoperative body temperature higher than $38.5{ }^{\circ} \mathrm{C}$ after the operation: 5 of these patients improved after symptomatic treatment without the use of antibiotics, and the remaining 5 patients were diagnosed with urinary tract infection. The incidence of urinary tract infection in our study (4.6\%) was higher than rates of $1-1.8 \%$ reported in the literature $[10,11]$, and we speculate that there may be three reasons for this. First, our study had a small sample size. Second, stone burden was larger in our study than in the previous studies, which may have resulted in more bacteria being released from the stone during the process of laser lithotripsy. Third, our study included more cases with renal calculi, whereas the prior studies mainly included patients with ureteral calculi.

There was one case of flash pulmonary edema in $37{ }^{\circ} \mathrm{C}$ group. It has been reported that elevating the temperature of the irrigation fluid increases the amount that is absorbed by the body [26]. Therefore, for the same irrigation pressure and duration of surgery, it would be expected that patients in $37{ }^{\circ} \mathrm{C}$ group would have absorbed a greater volume of fluid than patients in the other groups. As a result, high-temperature irrigation fluid is more likely to cause volume overload and lead to pulmonary edema than low-temperature irrigation fluid, especially in elderly patients. However, the risk of irrigation fluid absorption during flexible ureteroscopy is lower than that during TURP or PCNL because flexible ureteroscopy causes far less tissue injury than TURP and uses a smaller perfusion pressure than PCNL [27]. However, there remains a risk of increased fluid absorption for warmed irrigation fluid, which needs further study. Therefore, decisions as to whether or not to warm the irrigation fluid and the degree of warming necessitate full consideration of factors such as the predicted duration of surgery and cardiovascular risk of the patient, among others.

In addition, there was one case of postoperative bleeding in $37^{\circ} \mathrm{C}$ group, but the bleeding stopped after irrigation for $24 \mathrm{~h}$ using a three-cavity catheter. By contrast, there were no cases of bleeding in the other two groups, raising the possibility that warming the irrigation fluid might increase the risk of bleeding. Cao et al. reported that the amount of blood lost during TURP did not differ significantly between warmed and room-temperature irrigation fluid [19]. However, Kati et al. found that the amount of blood loss during PCNL was significantly lower for patients irrigated with fluid at room temperature [20]. It will be necessary to further study the effects of irrigation fluid temperature on bleeding risk. Although the risk of bleeding is very low for most patients undergoing flexible ureteroscopy, it is higher for patients with coagulation dysfunction or on long-term oral anticoagulants.

One limitation of this study is that there was no calculation of the amount of irrigation fluid absorbed, although it should be noted that the methods used for this are not always very accurate [27]. In addition, patient comfort was not evaluated in our study.

\section{Conclusion}

The use of heated irrigation fluid during flexible ureteroscopic lithotripsy can reduce the incidences of postoperative fever and shivering. However, further research is needed to establish the optimal temperature of the irrigation fluid while taking into account local heating effects caused by laser lithotripsy. In addition, decision-making regarding the temperature of the irrigation fluid should also take into consideration the cardiovascular risk of the individual patient and the predicted duration of surgery so as to avoid excessive absorption of irrigation fluid during the operation.

\section{Abbreviations}

ASA: American Society of Anesthesiologists; CT: Computed tomography; ESWL: Extracorporeal shock wave lithotripsy; PCNL: Percutaneous nephrolithotomy; PCT: Serum procalcitonin; TURP: Transurethral resection of the prostate; WBC: White blood cell count.

\section{Acknowledgements}

We thank the patients and their caregivers for participating in this trial.

\section{Authors' contributions}

Study Concept and Design: YH, YGF; Acquisition of Data: LL, MZ, LPM, QJP, QZ;

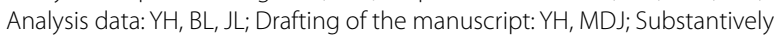
revised the work: YH, YMK, YGF, JH, TY, YL. All authors have read and approved the manuscript.

\section{Funding}

This work was supported by the Scientific Research Project of the Health Commission of Sichuan Province (No. 16PJ525).

\section{Availability of data and material}

Records and data pertaining to this study are in the patient's secure medical records in Suining Central Hospital and are available from the corresponding author on reasonable request. 


\section{Declarations}

\section{Ethics approval and consent to participate}

The present study, including its research protocols and data collection, were approved by the Ethics Committee of Suining Central Hospital. The study followed the principles outlined in the Declaration of Helsinki. All patients provided written informed consent.

\section{Consent for publication}

Not applicable.

\section{Competing interests}

The authors declare that they have no competing interests.

\section{Author details}

'Department of Urology, Suining Central Hospital, No. 127 Desheng W. Rd., Chuanshan District, Suining City 629000, Sichuan Province, People's Republic of China. ${ }^{2}$ Department of Urology, Institute of Urology, West China Hospital, Sichuan University, No. 37 Guoxue Alley, Wuhou District, Chengdu City 610041, Sichuan Province, People's Republic of China. ${ }^{3}$ Operation Room, Suining Central Hospital, No. 127 Desheng W. Rd., Chuanshan District, Suining City 629000, Sichuan Province, People's Republic of China. ${ }^{4}$ Department of Anesthesiology, Suining Central Hospital, No. 127 Desheng W. Rd., Chuanshan District, Suining City 629000, Sichuan Province, People's Republic of China.

Received: 21 November 2020 Accepted: 20 April 2021

Published online: 27 April 2021

\section{References}

1. Khan SR, Pearle MS, Robertson WG, et al. Kidney stones. Nat Rev Dis Primers. 2016;2:16008.

2. Alatab S, Pourmand G, El Howairis MF, et al. National profiles of urinary calculi: a comparison between developing and developed worlds. Iran J Kidney Dis. 2016;10(2):51-61.

3. Skolarikos A. Medical treatment of urinary stones. Curr Opin Urol. 2018;28(5):403-7.

4. Assimos D, Krambeck A, Miller NL, et al. Surgical management of stones: American Urological Association/Endourological Society Guideline. PART I J Urol. 2016;196(4):1153-60.

5. Assimos D, Krambeck A, Miller NL, et al. Surgical management of stones: american urological association/endourological society guideline, PART II. J Urol. 2016:196(4):1161-9.

6. Large T, Krambeck AE. Emerging technologies in lithotripsy. Urol Clin North Am. 2019:46(2):215-23.

7. Li JK, Teoh JY, Ng CF. Updates in endourological management of urolithiasis. Int J Urol. 2019;26(2):172-83.

8. Aldoukhi AH, Roberts WW, Hall TL, Ghani KR. Holmium laser lithotripsy in the new stone age: dust or bust? Front Surg. 2017:4:57.

9. Türk C, Skolarikos A, Neisius A, et al. EAU Guidelines on Urolithiasis. https://uroweb.org/guideline/urolithiasis. Accessed Jan 2019.

10. Perez EC, Osther PJS, Jinga V, et al. Differences in ureteroscopic stone treatment and outcomes for distal, mid-, proximal, or multiple ureteral locations: the Clinical Research Office of the Endourological Society ureteroscopy global study. Eur Urol. 2014;66(1):102-9.

11. Rosette JDL, Denstedt J, Geavlete P, et al. The clinical research office of the endourological society ureteroscopy global study: indications, complications, and outcomes in 11,885 patients. J Endourol. 2014;28(2):131-9.

12. Xu C, Song RJ, Jiang MJ, Qin C, Wang XL, Zhang W. Flexible ureteroscopy with holmium laser lithotripsy: a new choice for intrarenal stone patients. Urol Int. 2015;94(1):93-8.

13. Hyams ES, Munver R, Bird VG, Uberoi J, Shah O. Flexible ureterorenoscopy and holmium laser lithotripsy for the management of renal stone burdens that measure 2 to $3 \mathrm{~cm}$ : a multi-institutional experience. J Endourol. 2010;24(10):1583-8.
14. Cohen J, Cohen S, Grasso M. Ureteropyeloscopic treatment of large, complex intrarenal and proximal ureteral calculi. BJU Int. 2013;111(3 Pt B):E127-31.

15. Ma K, Huang XB, Xiong LL, et al. Beijing Da Xue Xue Bao Yi Xue Ban 2015;47(4):615-7

16. Takazawa R, Kitayama S, Tsujii T. Successful outcome of flexible ureteroscopy with holmium laser lithotripsy for renal stones $2 \mathrm{~cm}$ or greater. Int J Urol. 2012;19(3):264-7.

17. Ulker V, Cakmak O, Yucel C, Can E, Celik O, Ilbey YO. The efficacy and safety of bilateral same-session ureteroscopy with holmium laser lithotripsy in the treatment of bilateral ureteral stones. Minerva Urol Nefrol. 2019;71(2):174-80.

18. Zhang $H$, Hong TY, Li G, et al. Comparison of the Efficacy of ultra-mini PCNL, flexible ureteroscopy, and shock wave lithotripsy on the treatment of 1-2 cm lower pole renal calculi. Urol Int. 2019;102(2):153-9.

19. Cao J, Sheng $X$, Ding $Y$, et al. Effect of warm bladder irrigation fluid for benign prostatic hyperplasia patients on perioperative hypothermia, blood loss and shiver: a meta-analysis. Asian J Urol. 2019;6(2):183-91.

20. Kati B, Buyukfirat E, Pelit ES, et al. Percutaneous nephrolithotomy with different temperature irrigation and effects on surgical complications and anesthesiology applications. J Endourol. 2018;32(11):1050-3.

21. Doyle DJ, Garmon EH. American Society of Anesthesiologists Classification (ASA Class). In: StatPearls. Treasure Island (FL): StatPearls Publishing 2020.

22. Lee SH, Kim TH, Myung SC, et al. Effectiveness of flexible ureteroscopic stone removal for treating ureteral and ipsilateral renal stones: a singlecenter experience. Korean J Urol. 2013;54(6):377-82.

23. Dindo D, Demartines N, Clavien PA. Classification of surgical complications: a new proposal with evaluation in a cohort of 6336 patients and results of a survey. Ann Surg. 2004;240(2):205-13.

24. Doizi S, Traxer O. Flexible ureteroscopy: technique, tips and tricks. Urolithiasis. 2018;46(1):47-58.

25. Singh $R$, Asthana $V$, Sharma JP, Lal S. Effect of irrigation fluid temperature on core temperature and hemodynamic changes in transurethral resection of prostate under spinal anesthesia. Anesth Essays Res. 2014;8(2):209-15.

26. de Freitas FM, Andrade CM Jr, de Mello MJ, et al. Effect of temperature on fluidity of irrigation fluids. Br J Anaesth. 2011;106(1):51-6.

27. Guzelburc V, Balasar M, Colakogullari M, et al. Comparison of absorbed irrigation fluid volumes during retrograde intrarenal surgery and percutaneous nephrolithotomy for the treatment of kidney stones larger than 2 cm. Springerplus. 2016;5(1):1707.

28. Aldoukhi AH, Hall TL, Ghani KR, et al. Caliceal fluid temperature during high-power holmium laser lithotripsy in an in vivo porcine model. J Endourol. 2018;32(8):724-9.

29. Miglietta F, Faneschi ML, Lobreglio G, et al. Procalcitonin, C-reactive protein and serum lactate dehydrogenase in the diagnosis of bacterial sepsis. SIRS and systemic candidiasis Infez Med. 2015;23(3):230-7.

30. Kim HY, Lee KC, Lee MJ, et al. Comparison of the efficacy of a forced-air warming system and circulating-water mattress on core temperature and post-anesthesia shivering in elderly patients undergoing total knee arthroplasty under spinal anesthesia. Korean J Anesthesiol. 2014:66(5):352-7.

31. Canturk M, Hakki M, Kocaoglu N. Effects of isothermic irrigation on core body temperature during endoscopic urethral stone treatment surgery under spinal anesthesia: a randomized controlled trial. Urol J. 2020;17(1):1-7.

32. Okeke LI. Effect of warm intravenous and irrigating fluids on body temperature during transurethral resection of the prostate gland. BMC Urol. 2007;7:15.

\section{Publisher's Note}

Springer Nature remains neutral with regard to jurisdictional claims in published maps and institutional affiliations. 